\title{
Association studies of dopamine synthesis and metabolism genes with multiple phenotypes of heroin dependence
}

Yunxiao $\mathrm{Li}^{1 \dagger}$, Yongsheng Zhu ${ }^{1+}$, Jianghua Lai ${ }^{1,2}$, Xugang Shi ${ }^{1}$, Yuanyuan Chen ${ }^{1}$, Jinyu Zhang ${ }^{1}$ and Shuguang $\mathrm{Wei}^{1,2^{*}}$ (D)

\begin{abstract}
Background: Heroin dependence is a complex disease with multiple phenotypes. Classification of heroin users into more homogeneous subgroups on the basis of these phenotypes could help to identify the involved genetic factors and precise treatments. This study aimed to identify the association between genetic polymorphisms of DA synthesis and metabolism genes, including tyrosine hydroxylase (TH), DOPA decarboxylase (DDC), solute carrier family 6 member 3 (SLC6A3) and DA beta-hydroxylase (DBH), with six important phenotypes of heroin dependence.

Methods: A total of 801 heroin dependent patients were recruited and fourteen potential functional single nucleotide polymorphisms (SNPs) were genotyped by SNaPshot. Associations between SNPs with six phenotypes were mainly assessed by binary logistic regression. Generalized multifactor dimensionality reduction was used to analyze the gene-by-gene and gene-by-environment interactions.

Results: We found that $D B H$ rs $1611114 \pi$ genotype had a protective effect on memory impairment after heroin dependence $(P=0.002, \mathrm{OR}=0.610$ ). We also found that the income-rs12666409-rs129915-rs1611114 interaction yielded the highest testing balance accuracy and cross-validation consistency for memory change after heroin dependence.

Conclusions: Our results suggest that the memory change after heroin dependence was a result of a combination of genetics and environment. This finding could lead to a better understanding of heroin dependence and further improve personalized treatment.
\end{abstract}

Keywords: Dopamine, Heroin dependence, Phenotype, Memory

\footnotetext{
* Correspondence: weisg9676@163.com

†Yunxiao Li and Yongsheng Zhu contributed equally to this work.

'College of Forensic Science, School of Medicine, Xi'an Jiaotong University,

Xi'an 710061, Shaanxi, China

${ }^{2}$ Key Laboratory of Environment and Genes Related to Diseases, Ministry of

Education, Xi'an 710061, Shaanxi, China
}

C C The Author(s). 2020 Open Access This article is licensed under a Creative Commons Attribution 4.0 International License, which permits use, sharing, adaptation, distribution and reproduction in any medium or format, as long as you give appropriate credit to the original author(s) and the source, provide a link to the Creative Commons licence, and indicate if changes were made. The images or other third party material in this article are included in the article's Creative Commons licence, unless indicated otherwise in a credit line to the material. If material is not included in the article's Creative Commons licence and your intended use is not permitted by statutory regulation or exceeds the permitted use, you will need to obtain permission directly from the copyright holder. To view a copy of this licence, visit http://creativecommons.org/licenses/by/4.0/ The Creative Commons Public Domain Dedication waiver (http://creativecommons.org/publicdomain/zero/1.0/) applies to the data made available in this article, unless otherwise stated in a credit line to the data. 


\section{Background}

Drug dependence is a chronic relapsing brain disease that results from a combination of genetic and environmental factors [1], and the genetic factor accounts for approximately 30-60\% of the total risk $[2,3]$. Although multiple genes for the susceptibility to heroin dependence have been identified, a lot of these susceptibility genes could not be confirmed in subsequent studies, which further reminded us of the complexity of the genetic mechanism of heroin dependence. Heroin dependence is a complex disease with multiple phenotypes [4]. Classification of heroin users into more homogeneous subgroups on the basis of clinical and/or pathophysiological features could help to identify the involved genetic factors and precise treatments [4]. A previous study showed no significant association between the dopamine (DA) receptor D1 gene and opioid dependence in the overall analysis, but the association became apparent after stratifying based on the duration of the transition from first use to dependence (DTFUD) [5]. The DTFUD determined the addictive liability of the dependent patients $[5,6]$. Early opioid use was associated with higher rates of impulsivity and relapse of drug seeking behaviour [7, 8]. Individuals have different tolerances to heroin [9] or methadone [10] in terms of the amount required to achieve the same efficacy. Therefore, individuals require different doses of heroin or methadone. Heroin dependence leads to pathological memory formation and seriously affects normal working memory [11]. These phenotypes of heroin dependence vary widely among heroin dependent individuals and may be affected by genetic factors.

DA system modulates motivation, cognition and reward in the context of dependence [12-14]. Extracellular DA concentrations are the net result of release (exocytosis) and clearance (uptake) from the extracellular space. Tyrosine hydroxylase $(\mathrm{TH})$ converts L-tyrosine to L-DOPA, and then DOPA decarboxylase (DDC) catalyzes the decarboxylation of L-DOPA to generate DA [15]. The solute carrier family 6 member 3 (SLC6A3) encodes a DA transporter (DAT) that can re-uptake DA released into the synaptic cleft to the presynaptic terminal [16]. The DA beta-hydroxylase $(\mathrm{DBH})$ protein catalyses the oxidative hydroxylation of DA to norepinephrine [17]. These factors regulate extracellular DA concentrations at different levels.

The A allele of SLC6A3 rs27072 was associated with an early-onset age of nicotine dependence [18]. The frequency of the $\mathrm{G}$ allele of $T H$ rs6356 was significantly lower in the late-onset Parkinson's disease group [19]. Male ever-smokers with the AA genotype of $D B H$ rs5320 smoked fewer cigarettes per day [20]. Haplotype-based association analysis revealed a protective T-G-T-G haplotype of DDC rs921451rs3735273-rs1451371-rs2060762, which was significantly associated with nicotine dependence after correction for multiple testing [21]. However, the association of these genes with other important phenotypes of heroin dependence remained unclear.
We selected six phenotypes: memory change after heroin dependence, age of onset for heroin use, euphoria associated with first heroin use, DTFUD, daily heroin dose and daily methadone dose. We identified 14 potential functional single nucleotide polymorphisms (SNPs) by bioinformatics. We then analyzed the associations between the SNPs located in SLC6A3 (rs10064525, rs27072, rs1042098 and rs6347), TH (rs10770140, rs10770141, rs3842727 and rs6356), DDC (rs11575553 and rs12666409) and $D B H \quad(r s 129882, r s 129915$, rs1611114 and rs5320) with these phenotypes. We performed survival analysis for DTFUD. Finally, we analyzed the gene-by-gene and gene-by-environment interactions in these significant phenotypes.

\section{Methods}

\section{Subjects}

A total of 801 heroin-addicted individuals (mean age $39.30 \pm 8.291$ years) participated in our study. All of these participants were Chinese Han population. They were all unrelated individuals that were neither first-degree relatives, second-degree relatives nor third-degree relatives. This study included 709 males and 92 females. These participants were recruited from Lantian Compulsory Isolated and Detoxification Center, Xi'an Methadone Maintenance Treatment (MMT) Center and Xin'an Central Hospital Drug Rehabilitation Center. Heroin dependence was evaluated according to the Diagnostic and Statistical Manual of Mental Disorders fifth edition (DSM-V) criteria and a urine test. A structured interview was performed to assist with the diagnosis and to ask questions regarding (1) basic information: age, gender, nationality, education level, employment status, individual income, marital status and family atmosphere; (2) heroin use: the age of onset for heroin use, DTFUD, the daily dose of heroin used, reasons for first use of heroin, the administration routes of heroin, the euphoria associated with the first heroin use and the euphoria associated with heroin use after dependence; (3) individual responses after heroin use: body weight, sleep quality, memory, appetite and sexual desire; (4) methadone maintenance therapy or withdrawal symptoms: the number of withdrawal and relapse for heroin (absence of heroin use over 7 days counted as one withdrawal), the daily methadone dose used, and the methadone maintenance treatment duration. The detailed content of the questionnaire was shown in Supplementary file 1. Exclusion criteria were as follows: age $<18$ years old; dependence on other substances; presence of other neuropsychiatric diseases; and involvement in other clinical trials. A total of 737 (92\%) subjects were tobacco smokers in this study. All smokers consumed $<20$ cigarettes per day and did not meet the criteria for nicotine dependence according to the Fagerström Test for Nicotine Dependence (FTND, score of 4 or lower defined as no dependence). 
Written informed consent was obtained from all the study participants. The Ethical Committee of Xi'an Mental Health Center approved our study. We followed the approved guidelines to perform the protocol.

\section{SNP selection}

SNP selection criteria were as follows: (1) located in the promoter, intron-exon border, exon, the 3'near region and untranslated regions (UTRs) of gene; (2) the minor allele frequency (MAF) greater than 0.05 based on dbSNP Han Chinese Beijing (HCB) and HapMap databases; (3) each SNP had three genotypes. Then 5 SNPs in SLC6A3 (rs10064525, rs27072, rs1042098 and rs6347), 4 SNPs in TH (rs10770140, rs10770141, rs3842727 and rs6356), 2 SNPs in DDC (rs11575553 and rs12666409) and 4 SNPs in $D B H$ (rs129882, rs129915, rs1611114 and rs5320) were selected. Some important information of these SNPs was summarized in Table 1. Potential functional effects of these SNPs were predicted by SNP Function Prediction (FuncPred, https://snpinfo.niehs.nih.gov/snpinfo/snpfunc. html). Detailed effects of these SNPs were shown in Table S1 of Supplementary file 2.

\section{Genotyping}

The genomic DNA was extracted by E.Z.N.A ${ }^{\mathrm{Tm}}$ Blood DNA Midi Kit (Omega Bio-TeK, Norcross, GA, USA). Then, we used SNaPshot technology to genotype these SNPs. These specific experimental steps can be found in our previous research [22].

\section{Statistical analysis}

Hierarchical data on phenotype variables were used to identify subtypes, and associations between these subtypes with SNPs were first assessed by Pearson's chi-square test or Fisher's exact test. Then, these associations were assessed again by binary logistic regression, and the basic

Table 1 The information of selected SNPS

\begin{tabular}{|c|c|c|c|c|c|}
\hline Gene & Variable/ID & Allele & Gene location & Position (GRCh38.p7) & MAF \\
\hline \multirow[t]{8}{*}{$\overline{S L C 6 A 3}$} & rs10064525 & G & 3'near & 5:1392606 & 0.0921 \\
\hline & & $\mathrm{T}$ & & & \\
\hline & rs 27072 & T & $3^{\prime} U T R$ & $5: 1394407$ & 0.2051 \\
\hline & & C & & & \\
\hline & rs1042098 & G & 3'UTR & $5: 1394700$ & 0.2951 \\
\hline & & A & & & \\
\hline & rs6347 & C & Exon & $5: 1411297$ & 0.2985 \\
\hline & & $\mathrm{T}$ & & & \\
\hline \multirow[t]{8}{*}{$T H$} & rs10770140 & C & 5 'near & $11: 2172367$ & 0.3197 \\
\hline & & $\mathrm{T}$ & & & \\
\hline & rs10770141 & A & 5 'near & $11: 2172610$ & 0.3413 \\
\hline & & G & & & \\
\hline & rs3842727 & G & 3'near & $11: 2163618$ & 0.3576 \\
\hline & & T & & & \\
\hline & rs6356 & $\mathrm{T}$ & Exon & $11: 2169721$ & 0.4305 \\
\hline & & C & & & \\
\hline \multirow[t]{4}{*}{$D D C$} & rs11575553 & A & $3^{\prime} U T R$ & 7:50458521 & 0.0769 \\
\hline & & G & & & \\
\hline & rs12666409 & A & 5 'near & $7: 50567279$ & 0.2654 \\
\hline & & $\mathrm{T}$ & & & \\
\hline \multirow[t]{8}{*}{$D B H$} & rs129882 & $\mathrm{T}$ & $3^{\prime} U T R$ & 9:133658547 & 0.2554 \\
\hline & & C & & & \\
\hline & rs129915 & G & 3'near & 9:133659796 & 0.2698 \\
\hline & & A & & & \\
\hline & rs1611114 & $\mathrm{T}$ & $5^{\prime}$ near & 9:133635081 & 0.4101 \\
\hline & & C & & & \\
\hline & rs5320 & A & Exon & 9:133642351 & 0.1018 \\
\hline & & G & & & \\
\hline
\end{tabular}


information (age, gender, education level, employment status, individual income, marital status and family atmosphere) were set as covariates.

We assessed the potential correlation of DTFUD with these genotypes using Kaplan-Meier survival analysis. Survival curves were used to estimate the probability that individuals had not experienced dependence over a period of time following their first heroin use. The DTFUD was regarded as survival time in months. The origin of the first use was specified as the time of first heroin use, and the outcome of interest was the first occurrence of dependence. We used three methods (Wilcoxon, log rank and Tarone-Ware tests) to compare the survival curves, and these methods give varying weight to different phases of follow-up time.

We used generalized multifactor dimensionality reduction (GMDR; http://sourceforge.net/projects/gmdr/) to analyze the gene-by-gene and gene-by-environment interactions. This method permits adjustment for discrete and quantitative covariates and is applicable to both dichotomous and continuous phenotypes in various population-based study designs [23]. The multi-locus model with the maximum testing balance accuracy (Testing Bal. Acc) and cross-validation consistency (CV Consistency) was the best interaction model.

$P$ values were calculated based on our previous research [22] $P$ values were presented as two-sided, and the statistically significant was defined as $P<0.05$. We used Bonferroni's correction to adjust the significance level, and the $P$ value was divided by the total number of loci analyzed (15). Consequently the loci should be considered significant at $P<0.003$. All statistical analyses were performed using SPSS 20.0 software (SPSS, USA).

\section{Results}

\section{Association of $D B H$ with memory change after} dependence

For the phenotype of memory, a total of 586 subjects (73.2\%) that memory impaired were assigned to the "reduction" group, and 215 subjects (26.8\%) that memory no changed were assigned to the "no difference" group.
The frequency of $D B H$ rs1611114 TT genotype was significantly lower in the reduction group $(P=0.002$, $\mathrm{OR}=$ $0.610,95 \% \mathrm{CI}=0.445-0.835$, Table 2 ). This association was still significantly after adjustment of covariates $(P=$ 0.002 , OR $=0.607,95 \% \mathrm{CI}=0.440-0.837$, Table 2). These associations of other SNPs with memory change after dependence were listed in Table S2 of Supplementary file 2.

\section{SNPs and the age of onset for heroin use}

The age of onset for heroin use was converted to binary using median ( 28 years old), the sample was divided into earlier-onset $(n=440,54.9 \%)$ and later-onset $(n=361$, 45.1\%) groups accordingly.

After Bonferroni's correction, TH rs10770140 and rs10770141 were not associated with the age of onset for heroin use $(P=0.018$ and $P=0.015$, respectively, Table 3). These patients who carrying the rs10770140 TT genotype $(P=0.015, \quad$ OR $=0.599, \quad 95 \% \mathrm{CI}=0.395-$ 0.908 , Table 3$)$ or the $\mathrm{T}$ allele $(P=0.013$, OR $=0.604$, $95 \% \mathrm{CI}=0.405-0.901$, Table 3) were later-onset, but these findings were not observed after Bonferroni's correction. These patients who carrying the rs10770141 GG genotype $(P=0.012, \mathrm{OR}=0.577,95 \% \mathrm{CI}=0.374-0.890$, Table 3$)$ or the $\mathrm{G}$ allele $(P=0.010, \mathrm{OR}=0.580,95 \% \mathrm{CI}=$ $0.382-0.881$, Table 3 ) were later-onset, but these findings were not observed after Bonferroni's correction.

After Bonferroni's correction, these associations of rs10770140 TT $(P=0.019, \quad$ OR $=0.568,95 \% \mathrm{CI}=0.354-$ 0.912 , Table 3$)$ and rs 10770141 GG $(P=0.014$, OR $=0.538$, $95 \% \mathrm{CI}=0.328-0.881$, Table 3 ) genotypes with age of onset were still not significant after adjustment of covariates. These associations of other SNPs with age of onset for heroin use were listed in Table S3 of Supplementary file 2.

\section{SNPs and the euphoria of the first heroin use}

For the phenotype of euphoria, a total of 173 subjects (21.6\%) that have obvious feelings of euphoria were assigned to the "strong euphoria" group, and 628 subjects $(78.4 \%)$ that have minimal level of happiness, no

Table 2 The association between SNP and memory change after dependence

\begin{tabular}{|c|c|c|c|c|c|c|c|c|c|}
\hline \multirow[t]{2}{*}{ Gene } & \multirow[t]{2}{*}{ Variable/ID } & \multicolumn{2}{|c|}{ No change $(n=215)$} & \multicolumn{2}{|c|}{ Reduced $(n=586)$} & \multirow[t]{2}{*}{$P^{a}$} & \multirow[t]{2}{*}{$\mathrm{OR}, 95 \% \mathrm{Cl}$} & \multirow[t]{2}{*}{$p^{b}$} & \multirow[t]{2}{*}{$\operatorname{Exp}(B), 95 \% \mathrm{Cl}$} \\
\hline & & Number & Percent & Number & Percent & & & & \\
\hline & rs1611114 & & & & & $0.007^{n}$ & & $0.005^{n}$ & \\
\hline & $\pi$ & 111 & 51.6 & 231 & 39.4 & 0.002 & $0.610,0.445-0.835$ & 0.002 & $0.607,0.440-0.837$ \\
\hline & $\mathrm{TC}$ & 79 & 36.7 & 281 & 48.0 & $0.005^{n}$ & $1.586,1.150-2.187$ & 0.002 & $1.673,1.204-2.325$ \\
\hline & $\mathrm{CC}$ & 25 & 11.6 & 74 & 12.6 & 0.703 & $1.098,0.678-1.780$ & 0.956 & $0.986,0.600-1.620$ \\
\hline & $\mathrm{T}$ & 301 & 70.0 & 743 & 63.4 & $0.014^{n}$ & $0.742,0.585-0.942$ & & \\
\hline & C & 129 & 30.0 & 429 & 36.6 & & & & \\
\hline
\end{tabular}

$P^{\mathrm{a}}$ : Genotypic and allele frequency difference assessment by chi-square test

$P^{\mathrm{b}}$ : Genotypic and allele frequency difference assessment by binary logistic regression

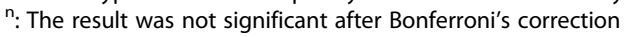


Table 3 The associations between SNPs and age of onset for heroin use

\begin{tabular}{|c|c|c|c|c|c|c|c|c|c|}
\hline \multirow[t]{2}{*}{ Gene } & \multirow[t]{2}{*}{ Variable/ID } & \multicolumn{2}{|c|}{ Age $\leq 28(n=440)$} & \multicolumn{2}{|c|}{ Age $>28(n=361)$} & \multirow[t]{2}{*}{$p^{a}$} & \multirow[t]{2}{*}{$\mathrm{OR}, 95 \% \mathrm{Cl}$} & \multirow[t]{2}{*}{$p^{\mathrm{b}}$} & \multirow[t]{2}{*}{$\operatorname{Exp}(\mathrm{B}), 95 \% \mathrm{Cl}$} \\
\hline & & Number & $\overline{\text { Percent }}$ & Number & $\overline{\text { Percent }}$ & & & & \\
\hline \multirow[t]{12}{*}{$\overline{T H}$} & rs10770140 & & & & & $0.018^{n}$ & & 0.092 & \\
\hline & $\pi$ & 366 & 83.2 & 322 & 89.2 & $0.015^{n}$ & $0.599,0.395-0.908$ & $0.019^{n}$ & $0.568,0.354-0.912$ \\
\hline & $\mathrm{TC}$ & 72 & 16.4 & 39 & 10.8 & 0.023 & $1.615,1.064-2.452$ & 0.032 & $1.681,1.047-2.703$ \\
\hline & $\mathrm{CC}$ & 2 & 0.5 & 0 & 0.0 & 0.504 & $1.005,0.998-1.011$ & 0.999 & $0.000,0.000-$ \\
\hline & $\mathrm{T}$ & 804 & 91.4 & 683 & 94.6 & $0.013^{n}$ & $0.604,0.405-0.901$ & & \\
\hline & C & 76 & 8.6 & 39 & 5.4 & & & & \\
\hline & rs10770141 & & & & & $0.015^{n}$ & & 0.071 & \\
\hline & GG & 371 & 84.3 & 326 & 90.3 & $0.012^{n}$ & $0.577,0.374-0.890$ & $0.014^{n}$ & $0.538,0.328-0.881$ \\
\hline & GA & 67 & 15.2 & 35 & 9.7 & 0.019 & $1.673,1.083-2.585$ & 0.024 & $1.77,1.080-2.907$ \\
\hline & $A A$ & 2 & 0.5 & 0 & 0.0 & 0.504 & $1.005,0.998-1.001$ & 0.999 & $0.000,0.000-$ \\
\hline & G & 809 & 91.9 & 687 & 95.2 & $0.010^{n}$ & $0.580,0.382-0.881$ & & \\
\hline & $A$ & 71 & 8.1 & 35 & 4.8 & & & & \\
\hline
\end{tabular}

$P^{\text {a }}$ : Genotypic and allele frequency difference assessment by chi-square test

$P^{\mathrm{b}}$ : Genotypic and allele frequency difference assessment by binary logistic regression

${ }^{n}$ : The result was not significant after Bonferroni's correction

euphoria or unclear were assigned to the "week euphoria" group.

After Bonferroni's correction, TH rs10770140 ( $P=$ 0.047 , Table 4) and rs10770141 $(P=0.035$, Table 4) were not associated with the intensity of euphoria. The subjects carrying the rs10770140 CC $(P=0.046, \mathrm{OR}=$ $1.012,95 \% \mathrm{CI}=0.996-1.028$, Table 4$)$ or rs10770141 AA $\quad(P=0.046, \quad$ OR $=1.012, \quad 95 \% \mathrm{CI}=0.996-1.028$, Table 4) genotype had a stronger euphoric response to heroin, but this effect was not observed after Bonferroni's correction. These associations were not significant after adjustment for the covariates. These associations of other SNPs with the intensity of euphoria were listed in Table S4 of Supplementary file 2.

\section{SNPs and the daily dose of methadone or heroin}

For the phenotype of methadone dose, the sample was divided into a high methadone dose group $(n=285$, $44.9 \%)$ and a low methadone dose group ( $n=350$, $55.1 \%)$ based on the median daily methadone dose (45 $\mathrm{mg})$. For the phenotype of heroin dose, the sample was divided into a high heroin dose group $(n=375,46.8 \%)$ and a low heroin dose group $(n=426,53.2 \%)$ based on the median daily heroin dose $(0.5 \mathrm{~g})$. No SNP was

Table 4 The associations between SNPs and euphoria associated with the first heroin use

\begin{tabular}{|c|c|c|c|c|c|c|c|c|c|}
\hline \multirow[t]{2}{*}{ Gene } & \multirow[t]{2}{*}{ Variable/ID } & \multicolumn{2}{|c|}{ Weak $(n=628)$} & \multicolumn{2}{|c|}{ Strong $(n=173)$} & \multirow[t]{2}{*}{$P^{a}$} & \multirow[t]{2}{*}{ OR, 95\% Cl } & \multirow[t]{2}{*}{$p^{b}$} & \multirow[t]{2}{*}{$\operatorname{Exp}(B), 95 \% \mathrm{Cl}$} \\
\hline & & Number & Percent & Number & Percent & & & & \\
\hline \multirow[t]{12}{*}{ TH } & rs10770140 & & & & & $0.047^{n}$ & & 0.791 & \\
\hline & $\Pi$ & 538 & 85.7 & 150 & 86.7 & 0.729 & $1.091,0.667-1.785$ & 0.741 & $1.088,0.659-1.798$ \\
\hline & $\mathrm{TC}$ & 90 & 7.2 & 21 & 12.1 & 0.460 & $1.211,0.728-2.012$ & 0.460 & $1.215,0.724-2.037$ \\
\hline & $\mathrm{CC}$ & 0 & 0.0 & 2 & 1.2 & $0.046^{n}$ & $1.012,0.996-1.028$ & 0.999 & 7,208,139,313, 0.000- \\
\hline & $\mathrm{T}$ & 1166 & 92.8 & 321 & 92.8 & 0.970 & $1.009,0.637-1.598$ & & \\
\hline & C & 90 & 7.2 & 25 & 7.2 & & & & \\
\hline & rs10770141 & & & & & $0.035^{n}$ & & 0.593 & \\
\hline & GG & 544 & 86.6 & 153 & 88.4 & 0.529 & $1.181,0.703-1.986$ & 0.515 & $1.192,0.702-2.025$ \\
\hline & GA & 84 & 6.7 & 18 & 10.4 & 0.299 & $1.329,0.775-2.278$ & 0.283 & $1.351,0.780-2.342$ \\
\hline & AA & 0 & 0.0 & 2 & 1.2 & $0.046^{n}$ & $1.012,0.996-1.028$ & 0.999 & $7,208,139,313,0.000$ \\
\hline & G & 1172 & 93.3 & 324 & 93.6 & 0.827 & $0.947,0.583-1.539$ & & \\
\hline & A & 84 & 6.7 & 22 & 6.4 & & & & \\
\hline
\end{tabular}

$P^{\mathrm{a}}$ : Genotypic and allele frequency difference assessment by chi-square test $P^{\mathrm{b}}$ : Genotypic and allele frequency difference assessment by binary logistic regression

$\mathrm{n}$ : The result was not significant after Bonferroni's correction 
associated with the daily dose of methadone or heroin use (Table S5 and S6 of Supplementary file 2, respectively).

\section{SNPs and DTFUD}

For the phenotype of DTFUD, the sample was divided into a long duration group $(n=376,46.9 \%)$ and a short duration group ( $n=425,53.1 \%)$ based on the median of DTFUD (1 month). No SNP was associated with DTFUD in either Pearson's chi-square test (Table S7 of Supplementary file 2) or the Kaplan-Meier survival analysis (Fig. S1 of Supplementary file 3).

\section{Gene-by-gene and gene-by-environment interactions}

The one- to four-way gene-by-gene and gene-byenvironment interaction models of the memory change after dependence were analyzed by GMDR.

For the phenotype of memory change after dependence, we found that these interactions in the one- to four-way models were significant. In two-way model (incomers3842727), income and rs3842727 have interaction. In three-way model (income-rs129915-rs1611114), income, rs129915 and rs1611114 have interaction. In four-way model (income-rs12666409-rs129915-rs1611114), income, rs12666409, rs129915 and rs1611114 have interaction. Among these significant interactions, the CV Consistency and Testing Bal. Acc in the four-way model (incomers12666409-rs129915-rs1611114) were the most significant, this model was the best model (Table 5).

These sequencing data of SNPs were listed in Supplementary file 4 .

\section{Discussion}

Heroin dependence is a heterogeneous disease, and its clinical features and therapeutic outcomes vary substantially among patients. Regardless of linkage analysis or associative analysis, the results are obviously affected by disease grouping within samples, which finally result in poor stability. Features that correlated with dependence could be used as indicators to categorize heroin dependent patients into subgroups with uniform disease features.

In this study, we demonstrated that $D B H$ rs1611114 was significantly associated with memory change after dependence. SNP rs1611114 was located in the 5'near region of $D B H$ and was predicted to be located in the transcription factor binding site (Table S8 of Supplementary file 2). Research found that $D B H-1021 \mathrm{C} / \mathrm{T}$ variant accounted for
$35-52 \%$ of the variation in plasma DBH activity, and the $\mathrm{T}$ allele predicted very low DBH activity [24]. Studies have also found that lower DBH expression levels lead to higher levels of extracellular DA and therefore have better working memory $[25,26]$. Hippocampal cannabinoid receptor 1 , found exclusively in DBH-expressing cells, was both necessary and sufficient to impair memory consolidation produced by acute stress [27]. DBH also modulated working memory and verbal and visual memory and sustained attention during the cannabis intoxication period [28]. These studies shown that rs1611114 may affect memory phenotype by regulating DBH expression. Similar to these findings, we found that the frequency of the rs1611114 TT in the memory reduction group was significantly lower, which indicated that subjects in the memory reduction group may have lower levels of extracellular DA and therefore have worse memory. Furthermore, income and $T H$ rs3842727 exhibited interactions in the memory change phenotype. Income, $D B H$ rs129915, rs1611114 exhibited interactions in this phenotype. Rs1611114, $D D C$ rs1266640, $D B H$ rs129915 and income also exhibited interactions in this phenotype. These results showed that the memory change phenotype was a result of a combination of genetics and environment. TH converts Ltyrosine to L-DOPA, DDC catalyzes the decarboxylation of L-DOPA to generate DA, and then DBH catalyses the oxidative hydroxylation of DA to norepinephrine. SNPs in these genes may interact with each other in regulating the concentration of DA, and then affected the memory change after heroin dependence. Research showed that the higher-income group had greater memory capacity [29]. Children from economically disadvantaged background showed lower memory performance and had a smaller hippocampal volume [30]. Lower income was associated with a flatter cortisol awakening response, blunted reactivity and recovery to acute stress [31]. Therefore, higher income may have a protective effect on memory impairment.

TH rs10770140 and rs10770141 were promoter variants that differentially affected the transcriptional activity of $\mathrm{TH}$ [32] (Table S9 and Table S10 of Supplementary file 2, respectively). Under basal circumstances and nicotine stimulation circumstances, the rs10770141 A and rs10770140 C alleles exerted a greater effect on TH transcription [32, 33]. However, after Bonferroni's correction, these associations of rs10770140 C

Table 5 Gene-by-gene and gene-by-environment interactions in phenotype of memory change after dependence

\begin{tabular}{lllll}
\hline Model & Training Bal. Acc & Testing Bal. Acc & CV Consistency & Sign Test $(P)$ \\
\hline Income & 0.5872 & 0.5900 & $10 / 10$ & $10(\mathbf{0 . 0 0 1 0})$ \\
Income rs3842727 & 0.5949 & 0.5651 & $4 / 10$ & $10(\mathbf{0 . 0 0 1 0})$ \\
Income rs129915 rs1611114 & 0.6280 & 0.5804 & $9 / 10$ & $9(\mathbf{0 . 0 1 0 7 )}$ \\
Income rs12666409 rs129915 rs1611114 & 0.6724 & 0.5946 & $10 / 10$ & $9(\mathbf{0 . 0 1 0 7 )}$ \\
\hline
\end{tabular}


and rs10770141 A alleles with age of onset for heroin use were not significant. These associations of rs10770140 CC and rs10770141 AA genotypes with the intensity of euphoria were still not significant after Bonferroni's correction. The $T H$ Val-81-Met polymorphism was found to be associated with early-onset alcoholism [34], as the $P$ value of this article was not corrected.

Some studies have found that SLC6A3 rs27072 may be related to the age of onset for tobacco or alcohol [35-37]. In particular, rs27072-A allele carriers were more likely to initiate smoking onset before 18 years old [36]. However, our research did not find that SLC6A3 rs27072 was related to the age of onset for heroin use. We proposed three hypotheses to explain the difference. First, our study excluded alcohol and nicotine dependent subjects. Second, the proportion of our sample that use heroin before 18 years old was relatively small (Fig. S2 of Supplementary file 3), and age of onset in our study was converted to binary using median (28 years old). Third, the mechanism of heroin dependence may different from that of alcohol and nicotine dependence.

\section{Conclusions}

In conclusion, our results supported the important role of $D B H$ rs 1611114 in memory change of heroin dependence. This phenotype was a result of a combination of genetics and environment. These findings were valuable for obtaining a better understanding of heroin dependence and improving personalized treatment.

\section{Supplementary information}

Supplementary information accompanies this paper at https://doi.org/10. 1186/s12881-020-01092-0.

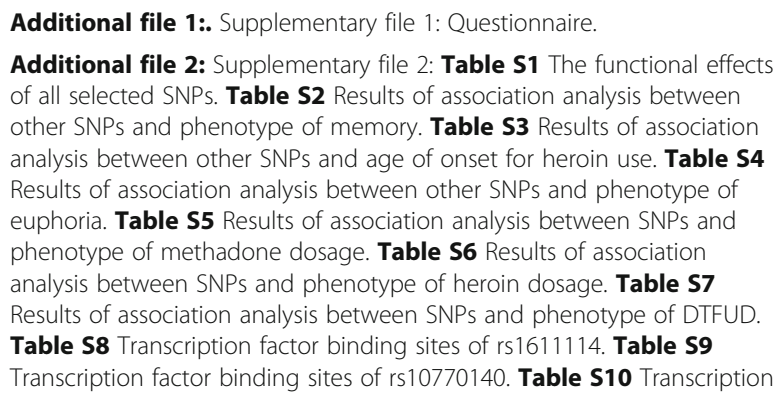

Additional file 3:. Supplementary file 3: Figure. S1. Kaplan-Meier survival analysis of DTFUD. Figure. S2. Frequency distribution of age of onset for heroin use.

Additional file 4:. Supplementary file 4: Sequence data.

\section{Abbreviations}

DA: Dopamine; DAT: DA transporter; DBH: DA beta-hydroxylase; DDC: DOPA decarboxylase; DSM-V: Diagnostic and Statistical Manual of Mental Disorders fifth edition; DTFUD: Duration of the transition from first use to dependence; FTND: Fagerström Test for Nicotine Dependence; GMDR: Generalized multifactor dimensionality reduction; HCB: Han Chinese Beijing; MAF: Minor allele frequency; MMT: Methadone Maintenance Treatment; SLC6A3: Solute carrier family 6 member 3; SNPs: Single nucleotide polymorphisms; TH: Tyrosine hydroxylase; UTRs: Untranslated regions

\section{Acknowledgments}

We warmly thank the participants for their contribution.

\section{Authors' contributions}

$Y L, Y Z, S W$ and $J L$ were responsible for the study concept and design; $Y L$ and $Y Z$ contributed to the acquisition of phenotype data and sample; $Y L, Y Z$, $X S, Y C$ and $J Z$ performed the genotyping; $Y L$ and $Y Z$ assisted with data analysis and interpretation of findings; $Y L$ drafted the manuscript; $Y L, Y Z, S W$ and $J$ provided critical revision of the manuscript for important intellectual content. All authors read and approved the final manuscript.

\section{Funding}

This work was supported by the National Natural Science Foundation of China (No. 81571856). The funding bodies played no direct role in the design of the study, the collection, analysis, or interpretation of data, or the writing of the manuscript.

\section{Availability of data and materials}

All the data supporting the conclusions of this article are presented within the manuscript or are available in the additional supporting file containing the supplementary material.

\section{Ethics approval and consent to participate}

Written informed consent was obtained from all the study participants. All participants read the informed consent, and we explained the relevant contents of the informed consent to them. Then all participants signed to agree to the relevant contents. This study protocol was approved by the Ethical Committee of the Medical College, Xi'an Jiaotong University.

\section{Consent for publication}

Not applicable.

\section{Competing interests}

The authors declare that they have no competing interests.

Received: 29 December 2019 Accepted: 15 July 2020

Published online: 31 July 2020

\section{References}

1. Vanyukov MM, Tarter RE. Genetic studies of substance abuse. Drug Alcohol Depend. 2000:59(2):101-23.

2. Kendler KS, Jacobson KC, Prescott CA, Neale MC. Specificity of genetic and environmental risk factors for use and abuse/dependence of cannabis, cocaine, hallucinogens, sedatives, stimulants, and opiates in male twins. Am J Psychiatry. 2003;160(4):687-95.

3. Tsuang MT, Lyons MJ, Meyer JM, Doyle T, Eisen SA, Goldberg J, et al. Cooccurrence of abuse of different drugs in men: the role of drug-specific and shared vulnerabilities. Arch Gen Psychiatry. 1998;55(11):967-72.

4. Sun J, Bi J, Chan G, Oslin D, Farrer L, Gelernter J, et al. Improved methods to identify stable, highly heritable subtypes of opioid use and related behaviors. Addict Behav. 2012;37(10):1138-44.

5. Zhu F, Yan CX, Wen YC, Wang J, Bi J, Zhao YL, et al. Dopamine D1 receptor gene variation modulates opioid dependence risk by affecting transition to addiction. PLoS One. 2013;8(8):e70805.

6. Ridenour TA, Maldonado-Molina M, Compton WM, Spitznagel EL, Cottler LB. Factors associated with the transition from abuse to dependence among substance abusers: implications for a measure of addictive liability. Drug Alcohol Depend. 2005:80(1):1-14.

7. Basu D, Ghormode D, Madan R, Mattoo S, Nehra R, Prabhakar S. Age of onset of dependence: does it help our understanding of opioid dependence by generating meaningful categories or by acting as a useful dimension? A critical examination of the classic debate in psychiatry. Indian J Psychiatry. 2014;56(3):228-37.

8. Chahua M, Sordo L, Barrio G, Domingo-Salvany A, Brugal MT, Molist G, et al. Non-fatal opioid overdose and major depression among street-recruited young heroin users. Eur Addict Res. 2014;20(1):1-7.

9. Warner-Smith $M$, Darke S, Lynskey M, Hall W. Heroin overdose: causes and consequences. Addiction. 2001;96(8):1113-25. 
10. Bell J, Burrell T, Indig D, Gilmour S. Cycling in and out of treatment; participation in methadone treatment in NSW, 1990-2002. Drug Alcohol Depend. 2006;81(1):55-61.

11. Yan WS, Li YH, Xiao L, Zhu N, Bechara A, Sui N. Working memory and affective decision-making in addiction: a neurocognitive comparison between heroin addicts, pathological gamblers and healthy controls. Drug Alcohol Depend. 2014;134:194-200.

12. Baik JH. Dopamine signaling in reward-related behaviors. Front Neural Circuits. 2013;7:152.

13. Chen W, Nong Z, Li Y, Huang J, Chen C, Huang L. Role of dopamine signaling in drug addiction. Curr Top Med Chem. 2017;17(21):2440-55.

14. Zilverstand A, Parvaz MA, Moeller SJ, Goldstein RZ. Cognitive interventions for addiction medicine: understanding the underlying neurobiological mechanisms. Prog Brain Res. 2016;224:285-304.

15. Chang $Y T$, Mues G, Hyland K. Alternative splicing in the coding region of human aromatic L-amino acid decarboxylase mRNA. Neurosci Lett. 1996; 202(3):157-60

16. Giros B, Caron MG. Molecular characterization of the dopamine transporter. Trends Pharmacol Sci. 1993;14(2):43-9.

17. Gonzalez-Lopez E, Vrana KE. Dopamine beta-hydroxylase and its genetic variants in human health and disease. J Neurochem. 2020;152(2):157-81.

18. Ling D, Niu T, Feng $Y$, Xing $H, X u X$. Association between polymorphism of the dopamine transporter gene and early smoking onset: an interaction risk on nicotine dependence. J Hum Genet. 2003;49:35.

19. Yan YP, Zhang B, Shen T, Si XL, Guo ZY, Tian J, et al. Study of GCH1 and TH genes in Chinese patients with Parkinson's disease. Neurobiol Aging. 2018; 68:159.e3-6

20. Ella E, Sato N, Nishizawa D, Kageyama S, Yamada H, Kurabe N, et al. Association between dopamine beta hydroxylase rs5320 polymorphism and smoking behaviour in elderly Japanese. J Hum Genet. 2012;57(6):385-90.

21. Ma JZ, Beuten J, Payne TJ, Dupont RT, Elston RC, Li MD. Haplotype analysis indicates an association between the DOPA decarboxylase (DDC) gene and nicotine dependence. Hum Mol Genet. 2005;14(12):1691-8.

22. Li Y, Qiao X, Yin F, Guo H, Huang X, Lai J, et al. A population-based study of four genes associated with heroin addiction in Han Chinese. PLoS One. 2016;11(9):e0163668

23. Xu HM, Xu LF, Hou TT, Luo LF, Chen GB, Sun XW, et al. GMDR: versatile software for detecting Gene-gene and Gene-environ- ment interactions underlying complex traits. Curr Genomics. 2016;17(5):396-402.

24. Zabetian CP, Anderson GM, Buxbaum SG, Elston RC, Ichinose H, Nagatsu T, et al. A quantitative-trait analysis of human plasma-dopamine betahydroxylase activity: evidence for a major functional polymorphism at the DBH locus. Am J Hum Genet. 2001;68(2):515-22.

25. Greenwood PM, Lin MK, Sundararajan R, Fryxell KJ, Parasuraman R. Healthy aging increases the cognitive effects of two genes that influence extracellular dopamine. Psychol Aging. 2014;29(2):363-73.

26. Parasuraman R, Greenwood PM, Kumar R, Fossella J. Beyond heritability: neurotransmitter genes differentially modulate visuospatial attention and working memory. Psychol Sci. 2005;16(3):200-7.

27. Busquets-Garcia A, Gomis-Gonzalez M, Srivastava RK, Cutando L, OrtegaAlvaro A, Ruehle S, et al. Peripheral and central CB1 cannabinoid receptors control stress-induced impairment of memory consolidation. Proc Natl Acad Sci U S A. 2016;113(35):9904-9.

28. Cosker E, Schwitzer T, Ramoz N, Ligier F, Lalanne L, Gorwood P, et al. The effect of interactions between genetics and cannabis use on neurocognition. A review Prog Neuropsychopharmacol Biol Psychiatry. 2018:82:95-106.

29. Lee S, Buring JE, Cook NR, Grodstein F. The relation of education and income to cognitive function among professional women. Neuroepidemiology. 2006;26(2):93-101.

30. Raffington L, Czamara D, Mohn JJ, Falck J, Schmoll V, Heim C, et al. Stable longitudinal associations of family income with children's hippocampal volume and memory persist after controlling for polygenic scores of educational attainment. Dev Cogn Neurosci. 2019;40:100720.

31. Raffington L, Prindle J, Keresztes A, Binder J, Heim C, Shing YL. Blunted cortisol stress reactivity in low-income children relates to lower memory function. Psychoneuroendocrinology. 2018;90:110-21.

32. Rao F, Zhang K, Zhang L, Rana BK, Wessel J, Fung MM, et al. Human tyrosine hydroxylase natural allelic variation: influence on autonomic function and hypertension. Cell Mol Neurobiol. 2010;30(8):1391-4.
33. Zhang K, Zhang L, Rao F, Brar B, Rodriguez-Flores JL, Taupenot L, et al. Human tyrosine hydroxylase natural genetic variation: delineation of functional transcriptional control motifs disrupted in the proximal promoter. Circ Cardiovasc Genet. 2010;3(2):187-98.

34. Dahmen N, Volp M, Singer P, Hiemke C, Szegedi A. Tyrosine hydroxylase Val-81-met polymorphism associated with early-onset alcoholism. Psychiatr Genet. 2005;15(1):13-6.

35. Schmid B, Blomeyer D, Becker K, Treutlein J, Zimmermann US, Buchmann $A F$, et al. The interaction between the dopamine transporter gene and age at onset in relation to tobacco and alcohol use among 19-year-olds. Addict Biol. 2009;14(4):489-99.

36. Ling $D$, Niu T, Feng $Y$, Xing $H, X u X$. Association between polymorphism of the dopamine transporter gene and early smoking onset: an interaction risk on nicotine dependence. J Hum Genet. 2004;49(1):35-9.

37. Genetic Study. The interaction between the dopamine transporter gene and age at onset in relation to tobacco and alcohol use among 19-yearolds. Addict Biol. 2009;14(4):489-99.

\section{Publisher's Note}

Springer Nature remains neutral with regard to jurisdictional claims in published maps and institutional affiliations.
Ready to submit your research? Choose BMC and benefit from:

- fast, convenient online submission

- thorough peer review by experienced researchers in your field

- rapid publication on acceptance

- support for research data, including large and complex data types

- gold Open Access which fosters wider collaboration and increased citations

- maximum visibility for your research: over $100 \mathrm{M}$ website views per year

At BMC, research is always in progress.

Learn more biomedcentral.com/submissions 